\title{
High value cost conscious care for diabetic patients at a community hospital
}

Eric Karu, Vahe Shahnazarian, Parag Mehta

New York Methodist Hospital, United States of America

\begin{abstract}
At New York Methodist Hospital (Brooklyn, NY), the pattern of ordering glucose testing was studied by a multidisciplinary committee because the medicine residents were placing inpatient chemstrip orders at their own discretion. It was found that chemstrip orders were being placed at inappropriate frequencies, and occasionally on inappropriate patients.

The staff and residents were educated on daily rounds in order to achieve the goal of reducing unwarranted fingersticks, consequently increasing patient satisfaction and reducing wasted time, resources, and costs. From April 2014 through March 2015 there were 274,889 fingersticks in the inpatient setting and following the intervention the number of fingersticks had decreased to 238,187 , representing a significant decrease.
\end{abstract}

\section{Problem}

At New York Methodist Hospital (Brooklyn, NY), the medicine residents were ordering chemstrips at their own discretion on inpatients. Unwarranted fingersticks were being ordered at inappropriate frequencies as well as on inappropriate patients on some occasions.

\section{Background}

According to the Center for Disease Control (CDC), diabetes mellitus is among the most commonly listed diagnoses for adults 18 years of age or older in the United States.[1] Diabetes is also the seventh most common cause of death in the US. Therefore adequate monitoring of blood sugar over the short and long term is crucial to preventing the development of preventable complications and comorbidities.[2]

As per Yale Diabetic Center, in the inpatient setting fingersticks should be started QID for all diabetic patients during the first 48 hours. Afterwards, if the patient is stable, their blood sugar is well controlled, and if on oral agent(s) or on one insulin injection/day, then the frequency of fingersticks can be brought down to BIDTID.[3] Unwarranted blood glucose testing in well controlled diabetic patients results in additional costs, a waste of resources, and it unnecessarily disturbs the patients. In April of 2010, the American College of Physicians (ACP) had announced their high value cost conscious care initiative. Their goal was to facilitate physicians to provide the best possible care for their patients, while simultaneously reducing the burden of cost on the health care system.[4] The ACP's initiative had made a strong impact on hospitals nationwide.

There is a multidisciplinary committee at New York Methodist Hospital which meets regularly to discuss high value cost conscious care issues. The committee consisted of attending and resident physicians, as well as nursing and hospital administration staff members. One such issue concerned fingersticks for the purpose of blood glucose testing.

\section{Baseline measurement}

It was decided that the main medical segments of the hospital be studied, which comprised of 15 units, including telemetry, the coronary care unit (CCU), and both medical and surgical intensive care units (ICUs). There are two main Accucheck units (Inform 1 and Inform 2) that transmit the collected data to a database. The data were collected every month and compared to the numbers after the intervention, which had occurred on April 15th 2014. It was found that 274,889 fingersticks were done on those units over a 12 month period, from April 2013 through March 2014.

See supplementary file: ds5175.png - "Fingersticks"

\section{Design}

Prior to the intervention (April 2013 through March 2014), it was found that there were 274,889 fingersticks done on the main medical units, so the pattern of glucose testing was studied through several multidisciplinary subcommittee meetings. They had found that patients without a diagnosis of diabetes were having fingersticks done for various reasons. They also found that the frequency and timing of chemstrip orders were variable and often ordered Q6 hours on patients on the regular units. A guideline was then developed to cut down on unnecessary glucose testing in an effort to provide high value cost conscious care to the patients. There was no restriction on the frequency of fingersticks for patients in the ICU, uncontrolled diabetic patients, or patients who may require more than a BID frequency of fingersticks. 
A rule and order set were created via the Cerner Electronic Medical Record (EMR). It was decided that providers may place an order for chemstrips if and only if a patient has a definitive diagnosis of diabetes mellitus. The frequency of fingersticks was also adjusted to BIDAC (before breakfast and dinner) in controlled diabetic patients.

\section{Strategy}

The staff and residents were educated on daily rounds in order to achieve the goal of reducing unwarranted fingersticks, consequently increasing patient satisfaction and reducing wasted time, resources, and costs. The study concerned the number of chemstrip orders on well controlled diabetic patients on the medical floors every month versus the number of admissions and number of inpatients with a diagnosis of diabetes mellitus.

The resident physicians and house staff were repeatedly educated on appropriate fingerstick testing. The Cerner EMR continues to allow residents to order fingersticks more frequently, but they are instructed to use their best judgment. A patient on a sliding scale will likely need blood glucose testing more frequently than a person on one low dose oral hypoglycemic.

\section{Results}

Prior to intervention / Post intervention

Apr-14: 21,515 / 24,700

May-14: 24,008 / 22,666

Jun-14: 22,789 / 20,415

Jul-14: $21,509 / 19,519$

Aug-14: 22,303 / 19,634

Sep-14: 21,516 / 17,365

Oct-14: 22,737 / 16,412

Nov-14: 20,264 / 15,106

Dec-14: 23,321 / 20,818

Jan-15: 26,309 / 21,328

Feb-15: 22,445 / 17,915

Mar-15: 26,173 / 22,309

Totals: 238,187 / 274,889

See supplementary file: ds5174.png - "Fingersticks"
We have learned that reaching a consensus with patient care guidelines among physicians is no easy task. Everyone has their own opinions on the appropriate management of diabetics, more specifically on the appropriate use of fingersticks for blood glucose monitoring. The reports demonstrate that the total number of fingersticks have decreased after the intervention was made. However, it should be taken into consideration that it does not indicate the total number of patients with a diabetic diagnosis and/or total number of admissions.

\section{Conclusion}

There is absolutely no question that patients with a diagnosis of diabetes mellitus should have their blood sugar checked regularly to prevent complications. The New York Methodist Hospital medical staff was educated on the new guidelines on BID fingerstick testing as recommended by the American Diabetic Association. Through the simple creation of an order set, placing a simple rule via the EMR, and educating the medical staff, we managed to curtail the unnecessary testing without compromising patient safety.

From April 2014 through March 2015 there were 274,889 fingersticks in the inpatient setting, and following the intervention the number of fingersticks had decreased to 238,187 , representing a significant decrease. This represents a significant reduction in costs in medical supplies (Chemstrips, lancets, alcohol pads) and man hours. In addition to reduced costs to the patient and hospital, there is also a reduction of pain and inconvenience, all the while preserving patient satisfaction.

\section{References}

1. Distribution of First-Listed Diagnoses Among Hospital Discharges with Diabetes as Any-Listed Diagnosis, Adults Aged 18 Years and Older, United States, 2010 Centers for Disease Control and Prevention (CDC), National Center for Health Statistics, Division of Health Care Statistics, data from the National Hospital Discharge Survey Data computed by personnel in CDC's Division of Diabetes Translation, National Center for Chronic Disease Prevention and Health Promotion.

http://www.cdc.gov/diabetes/statistics/hosp/adulttable1.htm Epub: October 01, 2014 Date Accessed: March 15, 2015.

2. American Diabetic Association; Statistics about Diabetes http://www.diabetes.org/diabetes-basics/statistics/ Date accessed March 23rd 2015

3. Inzucchi, Silvio E. MD; Endocrinology, TMP 534, Yale School of Medicine, Box 208020, New Haven, CT 06520.

4. ACP: ACP's High Value, Cost-Conscious Care Initiative; ACP American College of Physicians - Internal Medicine Doctors for Adults; Copyright 2015; https://www.acponline.org/clinical_information/resources/hvc cc.htm

American College of Physicians. Date Accessed March 23rd 2015

\section{Lessons and limitations}




\section{Declaration of interests}

Nothing to declare.

\section{Acknowledgements}

Cerner IT team at New York Methodist Hospital.

\section{Ethical approval}

Ethical approval was not necessary for this study because the aims of the intervention were to increase compliance with the accepted standard of care. There were no placebo or "non-intervention" arms of the study and the study itself was designed by our multidisciplinary committee. 